\title{
STRATEGI BISNIS KOPI MEREK COFFESSO PT DAVID ROY INDONESIA
}

\author{
Cindya Rienaya, Mudatsir Najamuddin* dan Akhmad Mahbubi
}

\begin{abstract}
ABSTRAK
Penelitian ini bertujuan untuk menentukan strategi bisnis yang cocok untuk PT. David Roy Indonesia. Matriks IFE, EFE, SWOT, dan QSPM digunakan untuk menganalisis data. Hasil dari matriks IFE menunjukkan bahwa kekuatan utama perusahaan adalah visi perusahaan dengan skor 0,486 dan kelemahan utama adalah lokasi pabrik dengan skor 0.280. Selain itu, hasil dari matriks EFE menunjukkan bahwa peluang utama adalah kebijakan pemerintah yang terkait dengan ekspor biji kopi dengan skor 0,397, dan ancaman utama adalah kebijakan pemerintah yang berkaitan dengan impor kopi olahan dengan skor 0,266. Analisis SWOT menghasilkan beberapa alternatif strategi dan matriks QSP menunjukkan bahwa strategi diferensiasi mendapatkan prioritas tertinggi.
\end{abstract}

Kata Kunci: strategi, kopi, IFE, EFE, SWOT, QSPM

\begin{abstract}
This study aims to determine suitable business strategies for PT. David Roy Indonesia. IFE matrices, EFE, SWOT, and QSPM were employed to analyze the data. Results from IFE matrices indicated that the company's main strength is the vision of company with a score of 0.486 and the main drawback is the location of the plant with a score of 0.280. In addition, results from EFE matrices indicated that the main opportunity is government policies related to the export of coffee beans with a score of 0.397, and the main threat is government policy related to the import of processed coffee with a score of 0.266. The SWOT analysis results several alternative strategies and QSP matrices indicated that resources differentiation strategy getting the highest priority of all.
\end{abstract}

Keywords: strategy, coffee, IFE, EFE, SWOT, QSPM

\section{PENDAHULUAN}

Coffe pods merupakan hasil penyempurnaan dari industri kopi bubuk dengan penggunaan konsep teknologi dari Italia. Coffee pods merupakan kopi bubuk dalam kemasan kertas yang berfungsi sebagai filter, sehingga aroma dan rasa kopi tetap terjaga. Proses penyajian coffee pods berbeda dengan proses penyajian pada kopi bubuk seduh. Coffee pods disajikan menggunakan mesin espresso praktis sehingga tersajilah ekstrak kopi tanpa meninggalkan ampas dicangkir. 
Salah satu perusahaan yang mengembangkan kopi pods yaitu PT David Roy Indonesia. PT. David Roy Indonesia sebagai pelaku bisnis food and beverage untuk coffee pods dengan brand Coffeesso dan teh celup brand Dilmah berusaha untuk mengembangkan bisnisnya ditengahtengah persaingan usaha dalam negeri yang semakin marak baik persaingan dengan produk lokal maupun produk impor. Perusahaan pesaing yang memproduksi coffee pod antara lain, Illy coffee pod (PT. Bahana Genta Victory) dengan market share 50\% untuk produk kopi pods, D'Angelo coffee pod (PT. Pronto Indonesia) yang memiliki pengalaman lebih dari (9 tahun) dan JH coffee (PT.POD Indonesia). PT.DRI mencoba untuk memperkenalkan salah satu jenis kopi espresso sachet dalam kemasan pod.

Coffesso hadir dengan konsep konsumen dapat menikmati ekstrak kopi atau espresso ala kafe di rumah. Coffesso memiliki beberapa seri seperti world series, world heritage, house blends, silver series dan Indonesian series. Biji kopi yang digunakan Coffesso merupakan kopi yang berasal dari berbagai negara dan beberapa berasal dari Indonesia seperti papua,mandailing dan kintamani.

Bidang pengolahan dan pemasaran produk Coffesso mengalami permasalahan dan tantangan. Pertama, budaya mengkonsumsi kopi tubruk di Indonesia menjadi tantangan untuk mengembangkan pasar coffee pod yang masih belum familiar di kalangan masyarakat, selain itu kesadaran masyarakat terhadap kualitas kopi yang baik masih minim, belum lagi kopi yang berkualitas premium lebih sering diekspor dan kopi yang berkualitas rendah digunakan untuk produksi kopi dalam negeri yang kemudian dinikmati oleh masyarakat Indonesia. Kedua, minimnya sarana dan prasarana pengolahan kopi dalam negeri sehingga menghambat proses pemasaran atau distribusi produk kopi. Ketiga, adanya pesaing (competitor) yang menghasilkan produk sejenis. Berdasarkan kondisi tersebut, maka PT.DRI diharapkan menciptakan strategi yang tepat dalam usaha memenangkan persaingan (PT DRI,2014).

\section{METODE PENELITIAN}

\section{Waktu dan Tempat Penelitian}

Penelitian ini dilakukan di PT.David Roy Indonesia yang bertempat di Jalan Panglima Polim Raya No. 100 Jakarta Selatan, Indonesia. Penelitian dilakukan pada bulan Mei-November 2014.

\section{Jenis dan Sumber Data}

Menurut Nazir (2013:55), metode yang digunakan dalam penelitian ini adalah metode deskriptif, yang merupakan suatu metode dalam meneliti status sekelompok manusia, suatu objek, suatu set kondisi, suatu sistem pemikiran, ataupun suatu kelas peristiwa pada masa sekarang. Tujuan dari penelitian deskriptif ini adalah untuk membuat deskripsi, gambaran atau lukisan secara sistematis, faktual dan akurat mengenai fakta-fakta, sifat-sifat serta hubungan antar fenomena yang diselidiki.

Jenis data penelitian yang digunakan adalah data kualitatif. Menurut Moleong (2007:54) data kualitatif merupakan data yang dikumpulkan berupa kata-kata, 
gambar, keterangan-keterangan seperti sejarah perusahaan, perencanaan, serta strategi yang dilakukan untuk memasarkannya dan bukan angka-angka. Penelitian ini mengangkat definisi jenis data kualitatif sebagai pendalaman dan pemahaman data yang dikumpulkan berupa kata-kata atau tulisan, gambar dan bukan angka yang bertujuan untuk menjelaskan, mendeskripsikan suatu kondisi atau keadaan yang terjadi dalam kehidupan nyata. Penelitian ini menggunakan dua jenis data yaitu :

\section{Data Primer}

Data primer adalah sumbersumber dasar yang merupakan bukti atau saksi utama dari kejadian yang lalu. Contoh dari data atau sumber primer adalah data yang dikumpulkan secara langsung dari para manajer perusahaan yang berkompetensi memberikan keterangan, foto-foto dan catatan-catatan resmi yang dibuat pada suatu acara atau pertemuan. Berikut responden dalam penelitian ini: Daru Darmawan (Direktur Operasional), Daniel Pranoto (Manajer Pemasaran), Hosea Benyamin (Manajer Penjualan Nasional), Lidya Ellen ( Manajer HRD)

\section{Data Sekunder}

Data sekunder adalah data atau informasi yang diperoleh melalui studi pustaka dengan mempelajari berbagai tulisan, buku, dan skripsi yang berhubungan dengan penelitian ini. Sumber sekunder adalah catatan tentang adanya suatu peristiwa, ataupun catatan-catatan yang jaraknya telah jauh dari sumber orisinil. Misalnya, keputusan rapat suatu perkumpulan bukan didasarkan dari keputusan (minutes) dari rapat itu sendiri, tetapi dari sumber berita dari surat kabar.

\section{Teknik Pengambilan Sample}

Menurut Susan Stainback (1988) dalam Soendari (2010), teknik pengambilan sample pada penelitian ini menggunakan teknik purposive sampling, dengan sample atau responden yang memiliki tanggung jawab dan wewenang serta pengambil kebijakan perusahaan. Dalam uji kebsahan dataterdapat dua macam validitas penelitian, yaitu validitas internal dan validitas eksternal. Validitas internal berkenaan dengan derajad akurasi desain penelitian dengan hasil yang dicapai. Aspek kebenaran dalam dalam penelitian ini melalui pengujian kredibilitas, Cara pengujian kredibilitas data atau kepercayaan terhadap data hasil penelitian kualitatif antara lain dilakukan dengan perpanjangan pengamatan, peningkatkan ketekunan dalam penelitian, Triangulasi, diskusi dengan teman sejawat, analisis kasus negatif, dan membercheck.

Pengujian transferability merupakan validitas eksternal dalam penelitian kuantitatif. Validitas eksternal menunjukkan derajad ketepatan atau dapat diterapkannya hasil penelitian ke populasi dimana sampel tersebut diambil. Nilai transfer ini berkenaan dengan pertanyaan, hingga mana penelitian dapat diterapkan atau digunakan dalam situasi lain (Sugiyono, 2009:287).

\section{Teknik Pengumpulan data}

Menurut Nazir (2013:55)

Teknik pengumpulan data dalam penelitian ini dilakukan dengan Studi lapangan, yaitu penelitian langsung pada objek perusahaan untuk mendapatkan data-data dan 
bahan yang diperlukan. Menurut Sugiyono (2009:137), beberapa teknik yang dapat digunakan adalah: Wawancara (Interview), yaitu mengadakan wawan cara dan tanya jawab secara langsung dengan pihakpihak yang terkait dengan penelitian ini, Pengamatan (Observasi), yaitu pengamatan langsung ke penelitian sehingga diperoleh data-data yang diperlukan. Dalam hal ini dengan mendatangi yang diambil, Kuesioner, yaitu metode pengumpulan data yang diperoleh langsung dari objek penelitian dengan cara menyebarkan kuisioner kepada pihak-pihak yang menjalani langsung kegiatan usaha dan memiliki wewenang dalam hal pegambilan keputusan untuk perusahaan serta dapat memberikan keterangan perusahaan, dan Studi kepustakaan, yaitu metode pengumpulan data yang diambil dari literatur dan buku-buku yang berhubungan dengan permasalahan yang diteliti.

\section{Metode Analisis}

Teknik perumusan strategi dapat diintegrasikan ke dalam kerangka pengambilan keputusan tiga tahap. Tahap input merupakan tahap perumusan yang terdiri atas matrik IFE dan matrik EFE, tahap kedua berfokus pada penciptaan alternatif strategi dan tahap ketiga yang merupakan tahap keputusan.

\section{Tahap Masukan (Input Stage)}

Tahap masukan (input stage) terdiri dari kegiatan mengidentifikasi faktor- faktor yang mempengaruhi suatu usaha yang meliputi analisis lingkungan eksternal, dan analisis lingkungan internal dengan menggunakan matriks EFE dan IFE. Analisis internal dilakukan untuk mengetahui kekuatan dan kelemahan yang dimiliki perusahaan. Identifikasi faktor-faktor strategis tersebut dimasukan dalam Internal Faktor Evaluation Matrix (IFE) . Analisis eksternal dilakukan dengan identifikasi faktor-faktors strategis eksternal perusahan ke dalam External Faktor Evaluation Matrix (EFE).

Tahap Pencocokan (Matching Stage)

\section{Matriks Grand Strategy}

Bentuk umum dari Grand Strategy matrix terdiri atas dua dimensi. Pertama adalah dimensi posisi persaingandan kedua adalah dimensi pertumbuhan pasar. Matriks ini terdiri atas empat kuadran dengan masing-masing kuadran memiliki alternatif strategi.

\section{Analisis SWOT}

Analisis situasi merupakan awal proses perumusan strategi. Selain itu, analisis situasi juga mengharuskan para manajer strategis untuk menemukan kesesuaian strategis antara peluang-peluang eksternal dan kekuatan-kekuatan internal, disamping memperhatikan ancaman-ancaman eksternal dan kelemahan- kelemahan internal. Mengingat bahwa SWOT merupakan akronim untuk strenght, weakness, opportunities dan threats dari organisasi, yang semuanya merupakan faktor-faktor strategis.

\section{Tahap Keputusan Matriks QSP ( Quantitive Strategic Planing)}

QSPM merupakan alat analisis yang digunakan untuk memutuskan strategi yang akan digunakan berdasarkan dari kemenarikan alternative-alternatif strategi yang ada. Perhitungan QSPM didasarkan kepada input dari bobot matriks 
internal ekternal, serta alaternatif strategi pada tahap pencocokan.

\section{HASIL DAN PEMBAHASAN}

\section{Identifikasi Faktor Internal dan Eksternal}

Identifikasi faktor internal dan eksternal PT DRI pada bisnis kopi coffesso merupakan hasil dari observasi, wawancara dan kuesioner yang ditujukan kepada responden yang bertindak sebagai pengambil keputusan di perusahaan. Berdasarkan hasil identifikasi faktor internal tersebut, didapat faktor kekuatan internal perusahaan dan faktor kelemahan pada internal perusahaan serta Faktor eksternal yaitu faktor peluang dan faktor ancaman bagi keberlangsungan bisnis perusahaan.

\section{Faktor Internal}

\section{Kekuatan ( Strenght )}

Berdasarkan hasil observasi, wawancara, pengamatan mendalam dan penyebaran kuesioner yang ditujukan pada empat manajer puncak sebagai responden, didapat enam faktor strategik internal yang dikatakan sebagai kekuatan (strenght) PT DRI.

1. Visi misi perusahaan

2. Sistem pengendalian manajemen

3. Fasilitas produksi dan operasi

4. Kualitas produk

5. Penelitian dan pengembangan

6. Variasi atau seri produk yang ditawarkan

\section{Kelemahan}

1. Lokasi pabrik

2. Harga produk

3. Promosi yang dilakukan

4. Kualitas Sumber daya manusia

Faktor Eksternal Peluang ( Opportunity )
1. Kebijakan pemerintah menggiatkan ekspor kopi baik dalam bentuk biji maupun olahan

2. Gaya hidup masyarakat urban

3. Perkembangan teknologi dan informasi

4. Daya tawar konsumen

\section{Ancaman}

1. Kebijakan pemerintah terkait impor kopi olahan

2. Harga bahan baku utama

3. Ketersediaan bahan baku kopi

4. Daya tawar pemasok

5. Persaingan diantara perusahaan yang ada

6. Fluktuasi mata uang

\section{Analisis Lingkungan PT DRI}

Analisis lingkungan internal dan eksternal PT DRI berikut akan menjabarkan kekuatan utama dan kelemahan utama serta peluang utama dan ancaman utama PT DRI dalam menghadapi persaingan bisnis.

\section{Matriks Evaluasi Faktor Internal (IFE)}

Berdasarkan IFE (Internal Factors Evaluation), didapat kekuatan utama PT DRI yaitu, visi dan misi perusahaan dengan skor 0,486. Visi PT DRI untuk memanjakan penikmat kopi yang menginginkan kualitas espresso yang terbaik, menjadikan model masa depan bagi coffesso yang menjadi komitmen dan milik bersama seluruh anggota perusahaan.

Kelemahan utama produk coffesso, terletak pada lokasi pabrik dengan skor 0,280. Lokasi pabrik yang berada di Malaysia menjadi kelemahan utama bagi bisnis coffesso. Lokasi pabrik yang berada jauh dengan lokasi bisnis PT DRI tidak efisien dari segi biaya dan 
menyulitkan karena banyaknya prosedur ekspor impor.

\section{Evaluasi Faktor Eksternal (EFE)}

Berdasarkan matriks EFE (External Factors Evaluation), peluang utama produk coffesso dalam memenangkan persaingan bisnis adalah kebijakan pemerintah terkait ekspor kopi dengan skor 0,397. Peraturan pemerintah terkait mempermudah ekspor biji kopi, memperlancar jalannya usaha produksi kopi POD coffesso, sehingga dengan adanya persediaan produk, maka PT DRI dapat melakukan tahap selanjutnya untuk mendistribusikan, mempromosikan dan memasarkan coffesso ke pasar dan lingkup bisnis sebagai target konsumen.

Ancaman utama dari lingkungan jauh perusahaan adalah kebijakan pemerintah terkait impor kopi olahan dengan skor 0,266. Kebijakan ini merupakan ancaman serius bagi keberlangsungan bisnis PT DRI dalam memasarkan coffesso. Kebijakan pemerintah redam impor kopi olahan terkait pentingnya menjaga mutu yang diproduksi oleh pelaku industri di Indonesia. Kemenperin akan menetapkan standar nasional indonesia (SNI) pada produk kopi instan yang diperdagangkan di Indonesia sehingga diharapkan bisa meredam masuknya kopi instan impor yang disinyalir bermutu rendah (Jurnal Asia,2014). Hal ini sangat berdampak pada persaingan bisnis coffesso dikala maraknya produk kopi yang beredar di pasar.

\section{Alternatif Strategi Matrik Grand Strategy}

Perusahaan yang berada pada kuadran I memiliki posisi strategis yang sempurna. Kondisi PT David Roy Indonesia yang memiliki produk kopi pods, mendukung diversifikasi terkait yang dapat membantu mengurangi resiko yang berkaitan dengan lini produk yang sempit.

PT DRI dapat mendukung strategi diversifikasi terkait, dimana apabila keadaan- keadaan berikut terjadi pada PT DRI:

a. Ketika perusahaan berkompetisi disebuah industri yang tidak mengalami pertumbuhan atau pertumbuhannya lambat.

b. Ketika menambahkan produk yang baru namun terkait akan secara signifikan mendongkrak penjualan produk saat ini.

c. Ketika produk baru namun terkait dapat ditawarkan dengan harga yang sangat bersaing.

d. Ketika produk yang baru namun terkait memiliki tingkat penjualan musiman yang dapat mengimbangi puncak dan jurang penjualan yang ada saat ini di perusahaan.

e. Ketika produk organisasi yang ada saat ini sedang dalam tahap penurunan dari siklus hidup produk.

f. Ketika organisasi atau perusahaan memiliki tim manajemen yang kuat

\section{Matriks SWOT}

Berdasarkan hasil identifikasi faktor strategis internal dan eksternal diatas, didapatkan kekuatankelemahan PT DRI yang diurutkan berdasarkan hasil perhitungan matrik IFE serta peluang dan ancaman berdasarkan matrik EFE. Hasil dari grand strategy diatas, menunjukan posisi perusahaan berada pada kuadran IV, dimana posisi tersebut 
berarti PT DRI mendukung strategi diversivikasi. Berdasarkan hasil tersebut, kemudian dirumuskan ke dalam matrik SWOT guna mendapatkan beberapa alternatif strategi yang dapat dijalankan PT DRI untuk bisnis coffesso.

\section{Isu Strategi berdasarkan Matrik SWOT}

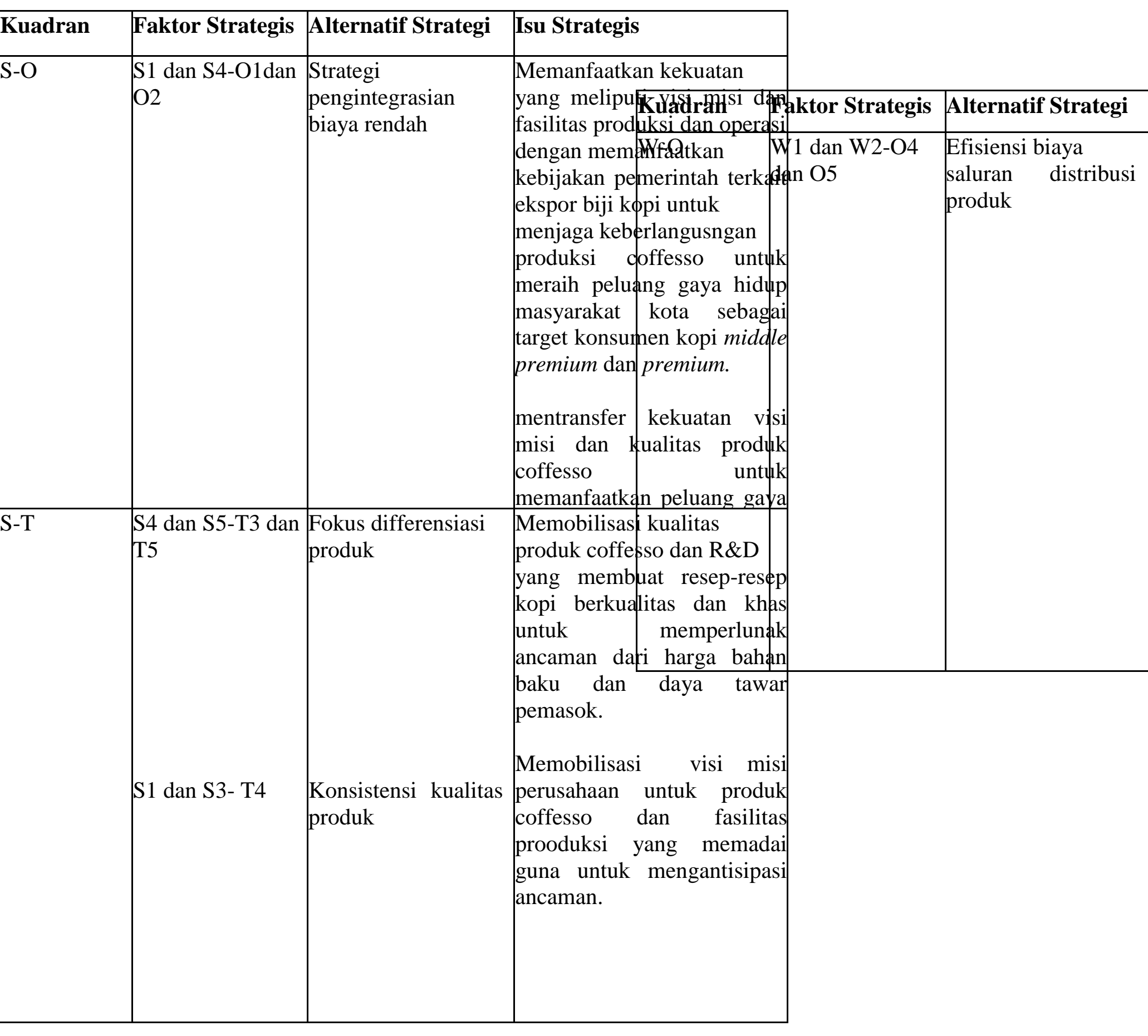




\begin{tabular}{|c|c|c|c|}
\hline W-T & $\begin{array}{l}\text { W1 dan W2 } \\
\text { T1,T2,T3 dan T4 }\end{array}$ & \begin{tabular}{|l|} 
Inovasi dalam \\
promosi produk
\end{tabular} & $\begin{array}{l}\text { Meminimalisir kelemahan } \\
\text { dalam hal promosi produk } \\
\text { karena terbenturnya biaya } \\
\text { promosi dengan mencari hal- } \\
\text { hal baru dalam promosi } \\
\text { untuk menghindari } \\
\text { kemiripan atau ancaman dari } \\
\text { pesaing yang memiliki } \\
\text { kelebihan dalam hal } \\
\text { promosi. } \\
\text { Meminimalisir kelemahan } \\
\text { lokasi pabrik yang jauh dan } \\
\text { harga produk yang tinggi } \\
\text { dari ancaman kebijakan } \\
\text { pemerintah terkait impor } \\
\text { kopi olahan, ketersediaan } \\
\text { dan harga bahan baku, serta } \\
\text { daya tawar pemasok. }\end{array}$ \\
\hline
\end{tabular}

\section{Formulasi Strategi Strategi S-O}

1. Strategi pengintegrasian biaya rendah

PT DRI memiliki posisi biaya rendah untuk berkonsentrasi pada produksi dan target strategisnya dengan differensiasi produk coffesso. Strategi ini dapat digunakan untuk memilih target yang paling aman terhadap produk pengganti atau dimana pesaing yang paling lemah berada.

2. Strategi Differensiasi Luas

Strategi ini menekankan pada sekumpulan tindakan yang terintegrasi, untuk menciptakan adanya perbedaan untuk barang atau jasa. Perbedaan yang ditawarkan adalah dengan menciptakan sesuatu keunikan yang diterima industrinya dan punya value bagi pelanggan.

\section{Strategi S-T}

1. Fokus Differensiasi Produk
Differensiasi diarahkan pada pasar luas dan melibatkan penciptaan sebuah produk atau jasa unik, yang membuat perusahaan harus menetapkan harga premium. Keunikan coffesso ini dapat dihubungkan dengan citra rancangan atau merek, teknologi, keistimewaan atau ciri khas, jaringan kerja distribusi, atau layanan terhadap konsumen.

2. Konsistensi pada kualitas
produk
Meningkatkan dan terus mempertahankan kualitas produk coffesso untuk memenuhi ekspektasi konsumen kopi di kota-kota besar. Kebijakan dan prosedur-prosedur ditetapkan untuk mengidentifikasi untuk pencapaian kualitas produk yang baik.

\section{Strategi W-O}

1. Efisiensi biaya saluran distribusi

Saluran distribusi yang efektif dan efisien dapat menjadi strategi 
bisnis yang tepat agar produk coffesso dapat mudah dan cepat berada dipasaran. Hal ini dikarenakan, lokasi pabrik yang berada jauh dari target pasar di kotakota besar Indonesia, sehingga diperlukan saluran distribusi yang efektif dan efisien sehingga dapat menghindari biaya lebih untuk produk sampai ke konsumen.

2. Memaksimalkan SDM yang ada Teknologi dan informasi pada era globalisasi ini sangat berkembang pesat. Hal ini dapat dimanfaatkan PT DRI untuk memaksimalkan kinerja sumber daya manusia yang ada diperusahaan. Komunikasi antar divisi untuk pertukaran informasi dan inovasi dalam hal mempromosikan produk coffesso dapat ditempuh dengan memanfaatkan perkembangan teknologi informasi yang ada saat ini.

diberikan berdasarkan kualitas, inovasi pada tingkat harga yang memuaskan. PT DRI sebagai pembeli biji kopi memerlukan suatu hubungan Prioritas Strategi Bisnis PT DRI

\section{Strategi W-T}

1. Inovasi dalam promosi produk

Tim pemasaran coffesso diharapkan selalu menggali ide-ide dalam hal memasarkan produknya. Inovasi dalam hal promosi produk dapat menjadi strategi bisnis untuk meraih pasar yang lebih luas. Divisi pemasaran diharapkan dapat menciptakan inovasi pemasaran yang belum pernah diterapkan perusahaan pesaing, sehingga PT DRI dapat menarik perhatian dan minat konsumen kopi.

2. Strategi pembelian dan just in time

Keputusan ini berkaitan dengan apa yang harus dibuat dan apa yang perlu dibeli. Pertimbangan yang

yang saling menguntungkan dengan pihak pemasok perkebunan kopi, agar menciptakan sistem pembelian yang efektif.

\begin{tabular}{|c|c|c|c|c|c|}
\hline \multirow[t]{2}{*}{ No } & \multirow[t]{2}{*}{ Prioritas Strategi } & & DivisiAS & Kuadran & Implement: \\
\hline & & \multicolumn{2}{|c|}{ Pemasaran } & \multicolumn{2}{|c|}{ KSWiQAn promosiyang efektif } \\
\hline 1 & Strategidifferensiasiluas & HRD & 6,5890 & MeseRrut & aryawanyang kol \\
\hline 2 & Strategipengintegrasian biaya ren & dopnju & $\operatorname{atan} 6,1620$ & Evallasi $\mathrm{k}$ & nerjapen \\
\hline 3 & Fokus differensiasiproduk & Prodt & Ksi 6,0860 & Mesife & tu prof \\
\hline 4 & Efisiensibiaya saluran distribusi & Peneth & 5,3590 & Me & ngkanres \\
\hline 5 & Konsistensikualitasproduk & & $\operatorname{tran} 5,2495$ & ${ }^{101}$ S9c110 & \\
\hline 6 & Memaksimalkan SDM yangada & & mbarig, & WO & \\
\hline 7 & Inovasidalampromosiproduk & & 5,0435 & WT & \\
\hline 8 & strategipembelian danjustin time & & 4,9242 & WT & \\
\hline
\end{tabular}

\section{Implikasi Manajerial}




\section{KESIMPULAN DAN SARAN}

\section{Kesimpulan}

1. Faktor internal berupa kekuatan perusahaan meliputi visi misi perusahaan, sistem pengendalian bisnis,fasilitas produksi dan operasi, kualitas produk, penelitian dan pengembangan, serta variasi produk yang ditawarkan. Kekuatan utama perusahaan terdapat pada visi misi perusahaan dengan skor 0,486 . Faktor internal berupa kelemahan yaitu; lokasi pabrik, harga produk, promosi yang dilakukan meliputi above the line, below the line dan event serta kualitas sumber daya manusia PT DRI. Kelemahan utama PT DRI dalam menjalankan bisnisnya terletak pada lokasi pabrik dengan skor 0,280. Faktor eksternal berupa peluang yakni; kebijakan pemerintah atas ekspor kopi biji maupun olahan, gaya hidup masyarakat urban, perkembangan teknologi dan informasi, dan daya tawar konsumen. Peluang utama PT DRI terdapat pada kebijakan pemerintah terkait ekspor kopi biji dan olahan dengan skor 0,397. Faktor eksternal berupa ancaman yaitu; kebijakan pemerintah terkait impor kopi olahan, ketersediaan bahan baku, harga bahan baku, persaingan diantara perusahaan yang ada, fluktuasi mata uang. Ancaman utama pada bisnis PT DRI yaitu kebijakan pemerintah terkait impor kopi olahan dengan skor 0,266.

2. Alternatif strategi yang dihasilkan dari perumusan matriks SWOT, yaitu strategi SO yang meliputi strategi pengintegrasian biaya rendah dan strategi differensiasi luas, strategi ST meliputi fokus differensiasi produk dan konsistensi kualitas produk, strategi WO yang meliputi efisiensi saluran distribusi dan memaksimalkan SDM yang ada, strategi WT yang meliputi inovasi dalam promosi produk dan strategi pembelian dan just in time.

3. Prioritas strategi yang didapat berdasarkan total TAS tertinggi pada matriks QSP yang dapat dijalankan PT David Roy Indonesia, yaitu strategi differensiasi luas dengan total skor 6,589 .

Saran

Beberapa saran yang dapat dilakukan PT David Roy Indonesia dalam menjalankan bisnis kopi coffesso yaitu:

1. Menjalankan prioritas strategi yaitu strategi differensiasi luas yangtelah dirumuskan oleh para pengambil kebijakan strategis perusahaan.

2. Mengevaluasi setiap kinerja yang telah dijalankan setiap 6 bulan sekali atau minimal setiap tahun.

3. Untuk mendukung strategi bisnis yang telah dirumuskan maka PT DRI membutuhkan lokasi produksi yang berada di Indonesia. Hal ini bertujuan agar strategi yang telah dirumuskan dapat berjalan lebih efektif dan efisien bagi keberlangsungan usaha PT DRI dalam memenangkan persaingan bisnis kopi di Indonesia.

* Alamat Koresponden: mudatsir@uinjkt.ac.id 